\begin{tabular}{cc}
\hline International Journal of Engineering \& Technology, $7(2.29)(2018) 682-687$ \\
SPC & Website: www.sciencepubco.com/index.php/IJET \\
Research paper & International Journal of Engineering \& Technology \\
\hline
\end{tabular}

\title{
Individual Education Program (IEP) Paperwork : A Narrative Review
}

\author{
Aniva Kartika ${ }^{1 *}$, Dewi Retno Suminar ${ }^{2}$, Mareyke M.W. Tairas ${ }^{3}$, Wiwin Hendriani ${ }^{4}$ \\ ${ }^{1,2,3,4}$ Faculty of Psychology, Airlangga University, Indonesia \\ ${ }^{1}$ Faculty of Psychology, University Of Surabaya, Indonesia \\ *Corresponding Author E-Mail: Aniva@Staff.Ubaya.Ac.Id
}

\begin{abstract}
Previous studies have shown that teachers understand the importance of Individual Education Program (IEP), but they consider the administrative tasks of IEP as a burden. This review aims to illustrate how long the teacher completed the IEP administrative tasks, to explain why teachers view IEP as a burden, and to describe the strategies to minimize obstacles related to the administrative burden of IEP. The procedure of narrative review is selecting journals based on the inclusion and exclusion criteria related to administrative burden of IEP paperwork. The result shows that teachers spend more time doing IEP paperwork than assessing students' assignments, communicating with parents, and sharing with colleagues. IEP paperwork takes up more than $10 \%$ of working time. The reasons IEP paperwork perceived as burdens are because of a large number of IEP forms and details, the multiple IEP service flow, the lack of knowledge of the personnel relating to the preparation or implementation of IEPs, the lack of assistance of administrative staff to complete the IEP paperwork, and the short/limited deadlines for administrative duties of IEP. The proposed strategies are improving appropriate technology, streamlining the contents of IEP forms, group IEP and increase the IEP administrative skills of the teachers.
\end{abstract}

Keywords: Narrative Review; Individual Education Program (IEP); Paperwork; Burden of Administrative Tasks

\section{Introduction}

Individual Education Program (IEP) is an inevitable part of education for children with special needs. IEP is a term whose scope is broad enough, not just as an individual teaching strategy. IEP is an illustration of the student's condition (strengths, weaknesses and learning needs), the learning plan, along with the accommodation required by the student, monitoring and means of communicating and documenting student progress $(1,2)$. Meanwhile, the definition proposed by (3) emphasizes more on the aspect of individual goals in the IEP. It is a statement about a series of educational goals for students that are individual and contains a description of support services that will be obtained by students to achieve the objectives of his/her education.

The primary benefit of Individualised Education Program (IEP) is the fulfillment of individual learning needs for students with special needs $(1,2)$. Furthermore, (4) explains that the IEP can meet the needs of these students due to prior assessment of the strategies required based on the individual student's condition (describing the baseline data/students profile) and then the material, methods will be accordingly accommodated or modified. All of these aspects are written in the IEP. (5) add that Individual Education Program (IEP) in the United States, is an essential component in the provision of appropriate for individuals with special needs, as the IEP will guide the implementation of the education service. IEP can provide services by the conditions of students with special needs because with the design of individual education programs, students can learn according to individual ability and speed of learning with the expectation that he/she will be able to master the targeted material.
In addition to providing benefits to students, IEP also benefits teachers and parents. The benefits of IEP for teachers, on the one hand, is to support the preparation of daily teaching plans, as well as an assessment tool to monitor whether students achieve learning objectives or not, and to improve communication and teamwork of IEPs. On the other hand, the benefits of IEP for the family is that the parent will understand the characteristics, strengths and weaknesses of the child, the present level of child's ability, and interests of the child. Parents' expectation will be more appropriate, since it is based on the IEP information. Parents also gain knowledge about the modification of the child's behavior and can monitor child development(6).

Given the benefits of IEPs in the optimization of potential students with special needs, there is a need to implement IEPs in providing this specialized educational service. The legality aspect supports the implementation of IEP in some countries, as in the releasing statute such as the Individual with Disabilities Education Act (IDEA) in the United States $(3,7)$. The existence of this law requires that educational institutions develop IEPs because there are legal sanctions if it is not implemented (8). In the UK, the legality of children's education services with special needs is guaranteed through the Education Act 1996 and the Education Regulations 2001 which is then accompanied by guidance for implementation through the SENCo Code of Practice. The SENCo Code of Practice recommends the preparation of IEPs for students with special needs (9). The similar education provision/service to students with special needs by providing IEP is also conducted in Portugal (10), Turkey(6), and Malaysia(11).

In Indonesia, inclusion education is supported by Statute no. 20 of 2003 on the National Education System which reads "that every citizen has equal education opportunity". Additionally, the 
Ministry of National Education Regulation No. 70 of 2009 supports the implementation of Inclusive Education for learners who have disabilities and gifted/talented. Details of the IEP as one of the necessary steps to implement the rule are described in the supplement of Inclusive Education - The IEP Model(12).

Even though teachers understand the benefits of $\operatorname{IEP}(6,11)$, however teachers consider the preparation of the IEP or IEP paperwork as an administrative burden $(11,13)$. (8) also notes that teachers continue to complain about administrative paperwork that accompanies the IEP even though they understand that if it is used as intended, IEP can guarantee the provision of educational services to suit the needs of the students. Professional paperwork is the documents, reports, brochures, and the likes that are expected to be filled, put to distribution, or submission by school personnel or parents with the expectation of meeting the federal, state, or local special education law or regulations or procedural requirement. Filing of paperwork is in line with the Study of State and Local Implementation and Impact of the Individuals with Disabilities Education Act (14). Individual education plans (IEPs), annual goals and objectives, behavioral plans, manifestation determination review materials, and student re-evaluation forms are examples of such paperwork.

The existence of the legal basis for IEP development also does not always guarantee its smooth implementation. In the United States,(15) found that teachers who did not develop IEP, considered that the IEP is more a legal requirement than a direction for planning instructional instruction. (16) also revealed that teachers of the special needs students feel overwhelmed with the administrative workload associated with the legal rules required for the preparation and execution of IEPs. These teachers perceive that the time spent in performing the administrative tasks reduces the time to attend special needs students. Teachers of special needs students who are new to teaching with little experience also report similar things on the administrative burden of IEP (17).

(18) showed that there were still weaknesses in the implementation of IEP in a private elementary school. Teachers explained that it because the teaching of students with special needs took much time so that administrative tasks (including compiling a complete IEP) was seen as time-consuming and less noticeable duties.

IEPs are an unattached aspect of the educational services of special needs students, but their preparation tends to be considered as administratively burdensome to teachers. Therefore, a systematic investigation/review of research articles on IEP administrative burden/IEP paperwork is deemed necessary.

The purpose of the Narrative Review in this paper is to answer the research questions as follows: (a) How does the quantity of time the teachers deploy for the paperwork associated with IEP? (b) Why is the compilation and implementation of IEP paperwork viewed by teachers as a constraint/burden? (c) How can schools or teachers minimize the constraints associated with IEP paperwork burdens?

\section{Methodology}

This paper uses the method of Narrative Review. Narrative Review is different from Narrative Synthesis (or commonly referred to as qualitative meta analysis) in areas such as follows:

Narrative Review is commonly used to describe general literature reviews and is usually less systematic or less transparent about how researchers conduct synthesis processes from various research results. A narrative review is a description of the variously related research results(19). In contrast, narrative synthesis is a part of a broader review process, which includes a systematic approach to tracking related research reports/journals, and an assessment of the quality of the studies (primary studies) of the journals used.

The approaches to reviewing literature are narrative reviews and systematic reviews. On the one hand, narrative reviews are the traditional approach and usually, do not include a section describing the methods used in the review. On the contrary, systematic reviews (or overviews) are syntheses of primary research studies that involves the description of specific, explicit and therefore reproducible methodological strategies to collect, classify, critically evaluate and synthesize all relevant issues on a specific topic(20).

However, the narrative review has its advantages; they are as follows: it is a useful educational article since it holds information together into a readable format. It presents a broad perspective on a specific topic and often describes the development, history or management of a problem. Narrative overviews can function to incite thought and debates. Some journals are not keen of narrative reviews since they lack systematic methods that should be employed to construct them (21).

\subsection{Narrative Review Procedure}

There are several stages in doing this narrative review. First, the authors searched and selected relevant studies on the topic. In addition to being based on the inclusion criteria and exclusion of primary studies, the selection of the article is also based on an outline analysis of the results of the study. There are many articles obtained from the database, but not all of the research findings are relevant to answer research questions about IEP paperwork. Furthermore, the authors sift through and classify the articles to answer the three research questions.

Narrative reviews can address several research questions and the selection criteria for inclusion of the articles may not be explicitly specified. Subjectivity in selecting journal articles is a major drawback of the narrative review that potentially leads to bias (1). Selection bias also needs to be considered in narrative reviews. Selection bias is a systematic bias in the selection of primary research studies that are included in the review. A reviewer may only select those studies that support his prior beliefs is an example of this bias. However, this bias may also be due to "publication bias", that is the tendency of researchers, reviewers and editors to submit or accept articles for publication based on the strength of the study results(20).

(1) explains that improvement of the quality of the narrative review is achievable by borrowing of methodologies aimed at reducing bias in the selection of articles for review and employing an effective bibliographic research strategy from systematic reviews. Presently, there is no consensus on the standard structure of narrative review, then the preferred format is the IMRAD (Introduction, Methods, Results, Discussion)

To enhance the quality of narrative reviews, (21) employed a narrative review rating scale and Academic Nutrition on Dietic provide a checklist to ensure a qualified narrative review. This paper uses the narrative review checklist from Academic Nutrition on Dietic (22) to minimize the systematic bias in narrative reviews.

\subsection{Primary Studies selection}

Primary Studies (articles examined in this paper) are traceable through e-journal databases: ScienceDirect, SpringerLink, Sage Journal Online, Proquest, EBSCO, and Emerald. Keywords used to search the studies are: 'IEP' (Individual Education Plan or Program), 'paperwork' and 'administrative'/'administration'. The author does not limit the published issue of research journals. In the next sub-section will be discussed inclusion criteria and exclusion of the studies being used.

\subsection{Inclusion Criteria}

Articles (primary studies) used in this narrative review include: (a) Studies generated from "IEP" and "administration" keyword, (b) Studies generated from "IEP" and "paperwork" keywords, (c) The studies used are not distinguished based on the methodological approach, so this narrative review is also based on the results of quantitative research, not only qualitative ones, (d) Monthly reports or annual reports on IEP paperwork/administration from sub-units of the Ministry of Education or related formal institu- 
tions, (e) Periodic bulletins containing IEP paperwork/administration topics, published by formal educational institutions or professional institutions, (f) unpublished dissertation.

\subsection{Exclusion criteria}

Research which not used in this narrative review are:

(a) Studies related to IEP in physical education, (b) Studies related to IEP in children with special needs with health problems, such as orthopedic impairment, (c) Studies related to IEP in early childhood education, (d) Studies on the topic of IEP administrative or IEP paperwork in foreign languages other than English.

\section{Results}

A total of 30 primary studies on IEP paperwork had been identified. They met the criteria for inclusion in this review and suitable to answer the research questions.

Table 1: Articles included in the narrative review

\begin{tabular}{|c|c|c|}
\hline Author & Year of publications & Aspect of IEP Paperwork \\
\hline$(23)$ & 2002 & Time spent on IEP paperwork \\
\hline (24) & 2004 & $\begin{array}{l}\text { Time spent on IEP paperwork } \\
\text { Strategies to minimize IEP paperwork }\end{array}$ \\
\hline (25) & 2009 & Time spent on IEP paperwork \\
\hline (26) & 2010 & Time spent on IEP paperwork \\
\hline (27) & 2010 & Time spent on IEP paperwork \\
\hline$(28)$ & 2012 & Time spent on IEP paperwork \\
\hline (29) & 2013 & Time spent on IEP paperwork \\
\hline (30) & 1996 & $\begin{array}{l}\text { Reason perceived IEP paperwork as } \\
\text { 'administrative burden' }\end{array}$ \\
\hline (13) & 1999 & $\begin{array}{l}\text { Reason perceived IEP paperwork as } \\
\text { 'administrative burden' }\end{array}$ \\
\hline$(31)$ & 2001 & $\begin{array}{l}\text { Reason perceived IEP paperwork as } \\
\text { 'administrative burden' }\end{array}$ \\
\hline (32) & 2010 & $\begin{array}{l}\text { Reason perceived IEP paperwork as } \\
\text { 'administrative burden' }\end{array}$ \\
\hline (33) & 2011 & $\begin{array}{l}\text { Reason perceived IEP paperwork as } \\
\text { 'administrative burden' } \\
\text { Strategies to minimize IEP paperwork }\end{array}$ \\
\hline (11) & 2012 & $\begin{array}{l}\text { Reason perceived IEP paperwork as } \\
\text { 'administrative burden' }\end{array}$ \\
\hline (6) & 2012 & $\begin{array}{l}\text { Reason perceived IEP paperwork as } \\
\text { 'administrative burden' }\end{array}$ \\
\hline (14) & 2013 & $\begin{array}{l}\text { Reason perceived IEP paperwork as } \\
\text { 'administrative burden' }\end{array}$ \\
\hline (34) & 1982 & Strategies to minimize IEP paperwork \\
\hline (35) & 1986 & Strategies to minimize IEP paperwork \\
\hline$(36)$ & 1998 & Strategies to minimize IEP paperwork \\
\hline (37) & 2000 & Strategies to minimize IEP paperwork \\
\hline (38) & 2001 & Strategies to minimize IEP paperwork \\
\hline (39) & 2003 & Strategies to minimize IEP paperwork \\
\hline$(40)$ & 2004 & Strategies to minimize IEP paperwork \\
\hline (41) & 2004 & Strategies to minimize IEP paperwork \\
\hline$(42)$ & 2005 & Strategies to minimize IEP paperwork \\
\hline$(5)$ & 2005 & Strategies to minimize IEP paperwork \\
\hline (43) & 2005 & Strategies to minimize IEP paperwork \\
\hline (2) & 2005 & Strategies to minimize IEP paperwork \\
\hline (44) & 2006 & Strategies to minimize IEP paperwork \\
\hline$(45)$ & 2013 & Strategies to minimize IEP paperwork \\
\hline (46) & 2013 & Strategies to minimize IEP paperwork \\
\hline
\end{tabular}

The review is presented in the following three subchapters, each to answer the three research questions.

\subsection{Quantity of Time Used by the Teacher or Related Professionals to Perform IEP Paperwork / Administra- tive Duties}

Attending to paperwork can be an extremely time consuming and labor intensive activity. Estimates have it that the average special education teacher spends five hours per week on paperwork(25). Furthermore, educators dedicate more of their time to complete paperwork than their duties. Duties such as grading papers, communicating with parents, sharing expertise with colleagues, supervising paraprofessionals, and attending IEP meetings combined(23).
In addition to planning and teaching, assessing tasks, scheduling and attending IEP meetings, special needs teachers spend more than $10 \%$ of their working time just to fulfill administrative tasks. (24) records such administrative tasks as printing and reproducing special needs notices to parents, collecting administrative tasks from other teachers, evaluating student progress and planning student transition from school activities to activities that lead to their independence. Furthermore, (24) also cites that only $50 \%$ of teachers with special needs students receive assistance from administrative or secretarial personnel perform such administrative duties. Meanwhile, in addition to the time spent on academic instruction and mentoring, the administrative activity of the special needs teacher takes up the third largest portion of $12 \%$ (27). In line with the above conditions, the SPeNSE (29) report describes that the average special educational needs teacher spends 5 hours per week to complete the forms and perform the IEP administrative tasks. They spend more time doing the IEP administrative tasks than assessing assignments, communicating with parents, sharing and discussing with other teachers, and attending IEP meetings. The time spent working on IEP paperwork equals the time spent preparing for learning. In fact, more importantly, 53\% of special needs teachers in primary and secondary schools report that these routine and administrative tasks interfere with their teaching duties(29). The similar condition applied for other professionals dealing with students with special needs. From the survey of professionals dealing with special needs education (e.g., speech language pathologist), the main challenge they face is the high number of administrative tasks, That is about $60 \%$ of the administrative burden they have to perform(26) and in the year of 2001 to 2010 , the percentage was higher, about $80-88 \%$ (28).

\subsection{The Reasons Why Teachers Perceive The IEP Paperwork As Administrative "Burdens"}

If the IEP is not done correctly, then IEP will only fulfill mere administrative functions but are less able to be a valuable tool to facilitate the advancement of students with special needs(30). In line with Cooper, (13) suggests that IEPs are not always applicable because teachers state that many administrative tasks load in planning and implementation of IEP. Difficulties in implementing and monitoring these IEPs may result in the simplification of IEP, but if so, then the benefits will also be questioned.

The following will explain some of the reasons why teachers view the IEP as having high administrative burdens.

a. Too many contents and details in IEP forms and paperwork

(47) reports that the IEP paperwork is considered the number one constraint that disrupts teaching. Teachers needed many hours to fill out IEP forms and writing reports in order to record the students' development.

(33) revealed in his research report that the most common source of paperwork is: (a) the administrative task of the IEP has a long and varied flow of forms, ranging from the pre-referral stage to the IEP evaluation stage, (b) Less alignment of data obtained from the education assessment report form with assessment reporting requirements for Department of Education, (c) Fulfillment of documentation requirements for non-infringing procedures, (d) Recording of student progress / process according to legal requirements, (e) Number of duplicates on the IEP reporting requirements, both on hard copy and soft copy, and on reporting to various related parties, with different forms, (f) Data collected for different indicators seems only to fulfill the reporting function, less significant for the learning process.

b. IEP service flow that involves many parties / personnels (33) discloses that the course of preparing the IEP which has a long flow and demanding excessive administration. The legal rule also demands a rigorous tracking or monitoring process, which inseparable from administrative work. Also, in the IEP process, monitoring of intervention agreements involving various parties is also required. Parents involvement are expected in the process of preparing and implementing the IEP, but from the findings of(33), it appears that many parents do not have access to technology so 
that surveys conducted on parents are still traditional, which will also bring its complexity.

c. Teachers' negative belief on IEP administrative duties

Special Education Teachers often negatively view professional paperwork. The most prominent criticism is that the IEP is time consuming and not of much use. (14). (31) also recognised that for novice special education teacher, paperwork task is overwhelming. In his study,(14) reveals that novice special education teachers had negative views of the IEP paperwork because of its numerous administrative tasks and perceived insignificant to teaching.

Kargin, Acarlar, Sucuoglu (6) revealed that $80 \%$ of teachers did not prepare the IEP. The reason for this behavior is rooted in the teacher's view of the 'paperwork burden' in the preparation and implementation of the IEP. Teachers tend to view the IEP only from the administrative matter, so the IEP has not been used as a guide. Teachers in Malaysia also tend to perceive the preparation of IEP as an administrative burden, given the large number of paperwork (11).

d. Lack of knowledge and skills of the parties/ personnel related to the preparation or implementation of IEP

(32) 's study of school counselors in Turkey, found that counselors tend to judge themselves less knowledgeable in IEP applications. The counselor also appraises that teachers' knowledge of the inclusion education was less accurate, as well as the limited number of staffs. Meanwhile, the booklet prepared by the Ministry of National Education on the IEP lacks the appropriate and valid information for teachers.

e. Lack of administrative staff assistance to complete the IEP paperwork

(33) mentions that the conversion of traditional administrative tasks (e.g., for IEP recording) to computerized, led to staff reductions, whereas administrative tasks that are computerized also suck up high enough teachers' time and energy.

f. Short deadline for IEP administrative duties

Often the time for IEP evaluation is at the end of the semester, which often coincides with national holidays (e.g., Christmas, New Year and Eid), so the deadline for administrative settlement is limited (33).

\subsection{Strategies to Minimize the Administrative "Burden" Of IEP}

Many often consider the process of preparing the IEP difficult because it requires knowledge of pedagogy, curriculum, instruction and regulation to be met (e.g., in the United States is IDEA), it also takes intensive time and energy to do so. What can be done so that the IEP administrative tasks which originally viewed as "burdens" can be perceived as "support"? The following research presented results that can provide ideas about which administration of IEP is considered effective.

(24) demonstrates four ways in which principals and classroom teachers can help ease the administrative burden of teachers for students with special needs. These are:

a.Providing sufficient time for completion of administrative tasks b.Limiting the number of students assigned to teachers who served as 'case managers'

c.Increasing administrative assistance (assistant) to teachers of special needs in the IEP process

d.Only complete the IEP administrative tasks on areas that will help teachers and students.

In addition to the strategies(24) discloses above, the other strategies to reduce the administrative burden of IEP are as follows:

a. Sophisticated IEP administrative technology

Some techniques/methods facilitate administrative tasks in the preparation of IEP to lessen teachers' administrative burden. One of them is by using software that can ease the paperwork's task. (39) states that IEP software programs, both computer-generated and Internet-based, can help reduce the administrative burden of IEP development and implementation. (2) explains that from the examples of IEP softwares being investigated, the software can help to simplify the process and to improve the efficiency of IEP development. The conseideration of IEP software's precision is based on 'form' or 'function'. What is meant by the accuracy of the form is a document that meets the rules/regulations while the functions associated with the benefits that can be obtained from the meaning of education resulting from the document. While this software has much help in the IEP development process, teachers should have the knowledge and ability to develop a good IEP, keeping in mind the standard of regulation(48).

Another related problem with IEP paperwork is the timeconsuming task of IEP development. When IEPs are developed with a paper-based system, teachers spend hours to copy goals, objectives, materials and resources onto the IEP form. (35) examine the implementation of a compatible software system to develop IEPs. The results are teachers, or staff members use this system to develop IEP, for example creating goals and objectives, storing students data, transcribing, and record keeping. They indicated that teachers who used IEP software spent less time writing IEPs and are comfortable with the IEP for instructional planning than did teachers using noncomputerized IEP systems.

(41) who studied teachers' view on electronic performance support system on IEP, found that teachers made substantial changes in the method they used to produce an IEP, that is, changes in data entry, manipulation of data, and printing. Teachers perceived that the software is an excellent tool to use, so they thought that it is worth the time and effort put in to learning how to use it.

Teachers in most states in the United States indicated that they felt helped by technological advances in IEP administration. Examples include the increased opportunities to access student data, web sites and electronic communication (email) reduces paper usage for copy and makes it easy to disseminate information, and computerization also facilitates IEP monitoring system (33).

Further more, (38) added that utilizing of such software, however, does not automatically guarantee good outcomes. The feature of IEP software differs significantly, and inadequate training of staff might hamper the results. If the IEP computerized program is used effectively, however, the best of these programs may improve efficiency in special education provision, while improves the quality of IEPs. One still has to consider their advantages and disadvantages. Consideration upon pro and contra of the software and hardware requirement, whether it will be a stand alone, distributed network or centralized network system, should be taken into account.

The quality of $1 \mathrm{EP}$ often depended on teacher expertise, so that it will be difficult for novice teachers. Computerization of this process can be an efficient and effective way to help the teacher. Teachers who plan to use computers to speed and maximize the IEP process have to consider the educational design (that is, Curriculum Analysis, diagnostic testing, and user as architect program) before system development(34). They also might consider these following areas when implementing a computerized IEP system: (1) The physical format of the IEP, (2) IEP updates and how they will be executed, (3) How computerization will meet organizational service needs, (4) The computer system will also serve as a lesson-planning/resource retrieval system.

In addition to the software,(45) proposes the use of forms/forms placed in Google Docs so easy to use them at any time. He revealed that administrative tasks could not be separated from the preparation of IEP. The important thing is how to get around it through the use of technology, so it does not become a burden (or Morgan term: nightmare) for related professionals.

b. Improving the efficiency of IEP forms and the flow chart of special needs education services

c. In simplifying the IEP model, (33) proposes recommendations for reducing the amount of time administrative tasks and improving efficiency, including streamlining and shortening the IEP report (by omitting some indicators), and changing the reporting period to bi-annual (not every academic year, or even every semester). All forms of reports should be relevant to improve student learning outcomes/abilities, not just for administrative pur- 
poses. Another recommendation comes from (40) which suggests that the administrative burden of IEP evaluation may be reduced by setting a longer period of IEP evaluation (more than one year). d. IEP services do not have to be individual

(46) offer solutions that services provided to students with special needs should not always be one on one but may take the form of scheduling in activity blocks, longer interval sessions but less often and flexible. Similar to what Rudebusch \& Wiechmann says, the IEP is not necessarily one on one (one IEP for one student with special needs). When there are special needs students in one class with the same baseline ability so that the learning objectives are the same, a Group Education Plan can be drawn up instead of preparing the IEP for each $(49,50)$

e. Increase the numbers and skills of special education teachers and administrative staff of IEP

(37) stated that there are many paperwork demands on special education teachers. Meanwhile, in teacher training, there is less time devoted to IEP paperwork and emphasizes more on communication issues. Therefore in teacher training programs for preparing future teachers is to shift focus from communication modality and spend more time on issues, such as IEP preparation. (36) states that para-educators can assist teachers, not only when giving instruction, but para-educators can also assist students with special needs so that teachers have more time to handle their administrative tasks. Also, (33) proposes to provide additional resources to support training of local LEA staff related to IEP reporting tasks. f. Revising the legal rules related to administrative burden Several $(5,42)$ suggest that the 2004 IDEA revision includes the reduction of IEP/Paperwork administration, simplification of forms and the development of the IEP process. For example, if there is parental disapproval of the IEP, no need to coordinate an IEP meeting involving the entire team; just to discuss with the related teachers. (43) also stated that the IDEA revision in 2004 appears to streamline the flow of IEP compilation and content and reduce the involvement of many parties in the determination of educational services listed in the IEP.

\section{Discussion}

IEP aims to provide the best educational services for students with special needs through the provision of learning that suits their needs. However, in practice, the IEP is even considered a burden by teachers, especially regarding the administrative tasks of the IEP. This paper deals with issues in the IEP administration. Similar to this paper, (51) also questioned the usefulness and efficacy of IEP. She states that in reality one of the problems faced when implementing IEP is paperwork. He also cites several studies that attempt to reduce the administrative burden of IEP through software. Meanwhile, (50) which reviews the literature about the IEP, indicating that one of the challenges to be faced by educational special needs coordinator is excessive paperwork, which affects the major tasks they have to do.

Through their research, (52) demonstrated that the need for clarification of the problems and restriction faced at each stage of the IEP implementation. Their results reveal that there is a risk that the IEP is only used to merely meet administrative requirements, at the time of audit of the quality of education. They proposed a suitability between the policy guidelines and the conditions in the field. Andreasson et al., think similarly to the recommendations put forward in this paper that rules of law or policy should consider difficulties in the field. One of the things that can be done is to revise the legislation to reduce the administrative burden of IEP. One of the things that can be done is to revise the legislation to reduce the administrative burden of IEP.

\section{Conclusion}

The administrative task of the IEP is important to be a valuable tool for facilitating the advancement of learning of students with special needs. Unfortunately, on the implementation, various re- search results reported that the IEP only fulfills administrative functions alone. The teacher's IEP paperwork seized more than $10 \%$ of working time. The administrative activity of the special needs teacher takes up the third largest portion of $12 \%$. Hence, teachers view the IEP administration /IEP paperwork as a burden. Given the high quantity of time that special needs teachers, as well as related professionals, need to perform the various IEP administrative tasks, it is worth examining further the reasons why teachers consider the IEP administration as an expense. Some reasons why the IEP is perceived as bringing administrative burdens to teachers, ranges from individual reasons such as teachers' negative beliefs on IEP to technical issues such as overload IEP forms and inappropriate use of technology.

Therefore, strategies to minimize the IEP administrative tasks burden as revealed from this narrative review can be followed up in the practice of IEP implementation in school. Strategies such as improving appropriate technology related to IEP, streamlining IEP form, and others listed above will make IEP be used to fulfill its function as a guideline in optimizing the potential of students with special needs and not just mere administrative fulfillment requirements.

\section{References}

[1] Ferrari R. Writing narrative style literature reviews. the European Medical Writers Association. 2015;24(4):230-5.

[2] Wilson, Lodato G, Michaels CA, Margolis H. Form versus Function : Using Technology To Develop Individualized Education Programs for Students with Disabilities. Journal of Special Education Technology. 2005;20(2):37-46.

[3] Dempsey I. The Use of Individual Education Programs for Children in Australian Schools. Australasian Journal of Special Education. 2012;36(1):21-31.

[4] Elliott SN, Kratochwill TR, McKevitt BC. Experimental Analysis of the Effects of Testing Accommodations on the Scores of Students with and without Disabilities. Journal of School Psycholog. 2001;39(1):3-24

[5] Gartin BC, Murdick NL. IDEA 2004 : The IEP. Remedial and Special Education. 2005;26(6):327-31.

[6] Sahin H. The development of individualized educational programs in Turkey IEP applications. Social and Behavioral Sciences. 2012;46:5030-4

[7] Telzrow CF. IDEA Amendments of 1997 : Promise or Pitfall for Special Education Reform ? Journal of School Psychology. 1999;37(1):7-28.

[8] Vogel C. The Individual Academic Plan. District Administration. 2006:1-4.

[9] Morris E. Special Educational Needs Code of Practice. London: Department for Education and Skills; 2001. 1-148 p.

[10] Miranda-correia LD. Special education in Portugal : the new law and the ICF-CY. Procedia - Social and Behavioral Sciences. 2010;9:1062-8

[11] Bandu SH, Jelas ZM. The IEP : Are Malaysian Teachers Ready ? Procedia - Social and Behavioral Sciences. 2012;47:1341-7.

[12] Suplemen Penyelenggaraan Pendidikan Inklusif - Model Program Pembelajaran Individual (PPI), (2007).

[13] Tod J. IEPs : Inclusive educational practices ? Support for Learning. 1999;14(4):184-8.

[14] Mehrenberg RL. Red Tape and Green Teachers: The Impact of Paperwork onnovice special education teachers. International Journal of Special Education. 2013;28(1):80-7.

[15] Margolis H, Truesdell LA. Do Special Education Teachers Use IEPs to Guide Instruction? The Urban Review. 1987;19(3):151-9.

[16] Nance E, Calabrese RL. Special education teacher retention and attrition : the impact of increased legal requirements. International Journal of Education Management. 2009;23(5):431-40.

[17] Boyer L, Lee C. Converting challenge to success : Supporting a new teacher of students with autism. The Journal of Special Education. 2001;35(2):75-83.

[18] Liem SH, Panjaitan LN, Kartika A, editors. Penyusunan Buku Petunjuk Pelaksanaan Tugas Guru Pendamping Khusus di Sekolah "X" (The preparation of the manual for the execution of special needs teachers tasks in the school "X"2014; Jakarta: UIN Jakarta Press.

[19] Popay JRHSA. Guidance on the Conduct of Narrative Synthesis in Systematic Reviews. 2006. 
[20] Cipriani A, Geddes J. Comparison of systematic and narrative reviews : the example of the atypical antipsychotics. Epidemiologia e Psichiatria Sociale. 2003;12(3):146-54.

[21] Green BN, Johnson CD, Adams A. Writing narrative literature reviews for peer-reviewed journals : secrets of the trade. Journal of Chiropractic Medicine. 2001;5(3):101-17.

[22] Dietic ANo. Narative Review Checklist. 2017. p. 1-

[23] Carlson, Elaine, Chen L, Schroll, Karen, Klein S. Study of Personnel Needs In Special Education Final Report of the Paperwork Substudy. 2002.

[24] Klein S. Reduction Special Education Paperwork. 2004.

[25] Suter JC, Giangreco MF. Exploring Special Education and Paraprofessional Service Delivery in Inclusion-Oriented Schools. 2009:81-94.

[26] Katz LA, Maag A, Fallon KA, Blenkarn K, Smith MK. What Makes a Caseload (Un)Manageable? School-Based SpeechLanguage Pathologists Speak. Language, Speech, and Hearing Services in Schools. 2010;41:139-52.

[27] Vannest KJ, Burke 'EMD, Payne 'ETE, Davis CR, Soares 'EDA. Electronic Progress Monitoring of IEP Goals and Objectives. 2010.

[28] Moore BJ. Five Common Documentation Questions-Answered ASHA Leader. 2012;17(4):22-4

[29] SpeNse. Paperwork in Special Education. 2013.

[30] Cooper P. Are Individual Education Plans a waste of paper ? British Journal of Special Education. 1996;23(3):115-9.

[31] Mastropieri MA. Is the glass half full or half empty ? Challenges encountered by first-year special education teacher. The Journal of Special Education. 2001;35(2):66-74

[32] Coskun YD. School counselors 'views about the individualized educational program practices. Procedia - Social and Behavioral Sciences. 2010;9:1629-33.

[33] Ahearn E. Paperwork in Special Education : Survey Findings. 2011. p. 1-8.

[34] Minick BA, School BA. The IEP Process Can Computers Help ? Academic Therapy. 1982;18(2):141-8.

[35] Ryan LBRCN. Computerized vs . Noncomputerized Individualized Education Programs : Teachers Attitudes , Time , and Cost. Journal of Special Education Technology. 1986;VIII(1):5-12.

[36] French NK. Working together: Resources Teacher and Paraeducators. 1998;19(6):357-68
[37] Miller KJ. Welcome to the real world : Reflections on teaching and administration. American Annals of the Deaf. 2000;145(5):404-10.

[38] Margolis H, Free J. Computerized IEP Programs : A Guide for Educational Consultants. Journal of Educational and Psychological Consultation. 2001;12(2):171-8.

[39] Fonssagrives D. Technology helps lighten the paperwork load. ASHA Leader. 2003;8(11):2003-

[40] Cirrin FM. Advocating for Workload Strategies. ASHA Leader. 2004;9(12):18-20.

[41] Paschall ED, Jr. An evaluation of an electronic performance support system implementation: Florida State University; 2004.

[42] Boswell S. New IDEA Law Brings Relief , Worry for School Clinicians. ASHA Leader. 2005;10(2):3-

[43] Smith TEC. IDEA 2004 : Another Round in the Reauthorization Process. Remedial and Special Education. 2005;26(6):314-9.

[44] Donovan EO. Computer - based IEP Writers. District Administration. 2006:1-3.

[45] Morgan R. Dominate Your IEP Data. ASHA Leader. 2013;18(4):26-7.

[46] Rudebusch, Judy, Wiechmann J. Time Block after Time Block. ASHA Leader. 2013;18(8):40-5.

[47] Hale L. Behind The Shortage Of Special Ed Teachers : Long Hours, Crushing Paperwork. 2015. p. 1-4.

[48] Wilson GL, Craig A. Form versus Function : Using Technology To Develop Individualized Education Programs for Students with Disabilities. Journal of Special Education Technology. 2005;20(2):37-46.

[49] Dept.ofChildProtection. Documented Plans Supporting Education for All. Guidelines for Implementing Documented Plans in Public Schools. 2011.

[50] Mitchell D, Hornby G. Review of the Literature on Individual Education Plans. 2010.

[51] Rodger S. Individual Education Plans Revisited : A Review of the Literature. International Journal of Disability, Development and Education. 1995;42(3):221-39.

[52] Andreasson I, Asp-onsjö L, Isaksson J. Lesson learned from research on individual educational plans in Sweden : obstacles, opportunities and future challenges. European Journal of Special Needs. 2013;28(4):413-26. 